American Journal of Pharmaceutical Education 2017; 81 (4) Article 72.

\title{
RESEARCH
}

\section{Career Progression of the Pharmacy/MBA Professional: Characterization and Perceptions of the Combined Degree}

\author{
Christopher J. Daly, PharmD, MBA, ${ }^{a}$ Sarah-Elizabeth L. Tierney, BS, ${ }^{a}$ Erin O'Brien, MBA, \\ Karl D. Fiebelkorn, MBA, ${ }^{a}$ David M. Jacobs, PharmD ${ }^{\mathrm{a}}$ \\ ${ }^{a}$ University at Buffalo School of Pharmacy and Pharmaceutical Sciences, Buffalo, New York \\ ${ }^{\mathrm{b}}$ University at Buffalo School of Management, Buffalo, New York \\ Submitted December 8, 2015; accepted March 2, 2016; published May 2017.
}

\begin{abstract}
Objectives. To characterize pharmacy/MBA professionals during their entry-level and current positions and to describe their attitudes and perceptions toward their combined degree.

Methods. A cross-sectional survey of University at Buffalo (UB) alumni who obtained both pharmacy and MBA degrees was used. An electronic survey was developed through collaboration with the UB School of Management and administered in winter 2015.

Results. A total of 68/115 (59\% response rate) pharmacy/MBA professionals responded to the survey. Post-graduate training was completed by $24 \%$ of respondents, and most commonly it was a residency program. After adjusting for inflation to 2014 dollars, the median entry-level salary for pharmacy/MBA professionals was $\$ 140,123$ (mean $=\$ 144,327)$ and this increased to $\$ 179,947($ mean $=\$ 205,623)$ for those in their current position. Practice settings for entry-level professionals included pharmaceutical industry (25\%) and chain pharmacies (18\%). Most respondents believed that a combined degree helped in career advancement (85\%) and made them more competitive in the job market $(90 \%)$.

Conclusion. Pharmacy/MBA professionals are well-compensated, work in a wide-range of professional settings, and have a high-level of satisfaction with their combined degree.

Keywords: dual PharmD/MBA degree program, master of business administration (MBA), career development, pharmacy education, management
\end{abstract}

\section{INTRODUCTION}

Dual degree programs are increasingly being offered at schools and colleges of pharmacy in the United States. ${ }^{1}$ These programs allow student pharmacists to obtain two degrees in less time it would take to obtain each degree separately and provide opportunities outside of traditional clinical or community pharmacy. The most commonly offered dual degree is a Doctor of Pharmacy (PharmD) combined with a graduate degree (MS or $\mathrm{PhD}$ ) in the pharmaceutical sciences. ${ }^{2}$ The most subscribed professional degree combined with a PharmD is a Master of Business Administration (MBA) degree, which is offered at 57 institutions in the US. ${ }^{1}$ The objective of a PharmD/MBA program is to instill the business background and skills necessary to enter leadership positions that demand knowledge of health sciences management. ${ }^{2}$ As a PharmD/MBA degree has gained in popularity, little is known about the graduates of these programs and their career trajectories.

Corresponding Author: David M. Jacobs, University at Buffalo School of Pharmacy and Pharmaceutical Sciences, 316 Kapoor Hall, Buffalo, NY 14214. Tel: 716-829-2134.

Fax: 716-829-6094. E-mail: dmjacobs@buffalo.edu
At the University at Buffalo, the pharmacy and MBA collaborative program is the longest and most established dual degree program within the university. The University at Buffalo Schools of Pharmacy and Management were first approved in 1972 to offer a combined BS Pharmacy/ MBA program. This program included 30 credit hours for the MBA in addition to the 130 credit hours for the pharmacy portion. This program continued until 1997 where the dual pharmacy/MBA program was initiated in its current 5 year format. Over 115 students have passed through the combined pharmacy/MBA degree program to date whether earned together or at separate times.

The 2005 American Association of Colleges of Pharmacy (AACP) White Paper identified 23 schools and colleges of pharmacy offering joint degree programs with 246 students enrolled in PharmD/MBA programs. ${ }^{4}$ Since this publication, the number of combined PharmD/MBA programs has increased nationwide with a subsequent rise in students graduating with both degrees. ${ }^{1}$ This article recognized that PharmD/MBA programs are not well characterized especially in regards to positions taken by 


\section{American Journal of Pharmaceutical Education 2017; 81 (4) Article 72.}

graduates of these programs, utilization of their management degree, and their career trajectories. Chumney and colleagues investigated student pharmacists graduating with an MBA, and found the average starting salary to be higher with a dual PharmD/MBA than non-dual degree students. ${ }^{5}$ Their inferences are limited only to the student pharmacists graduating with a PharmD/MBA as they did not assess past graduates of their program. The University at Buffalo has a long history in terms of its pharmacy and MBA degree programs, and we have a sample large enough to make meaningful conclusions about this population. The objectives of this study were to characterize pharmacy/MBA professionals during their entry level and current-day positions and to describe their attitudes and perceptions toward their combined degree.

\section{METHODS}

We used a cross-sectional, electronic survey to evaluate career outcomes and attitudes of University at Buffalo School of Pharmacy and Pharmaceutical Sciences

Table 1. Baseline Demographics of Pharmacy/MBA Graduates

\begin{tabular}{|c|c|}
\hline Participants & $\begin{array}{cl} & \mathrm{N}=68 / 115 \\
(59 \% & \text { Response Rate) }\end{array}$ \\
\hline Age & $49(25-85)$ \\
\hline \multicolumn{2}{|l|}{ Gender } \\
\hline Female & $19(28)$ \\
\hline Male & $49(72)$ \\
\hline Year graduated Pharmacy School & $1988(1951-2014)$ \\
\hline $\begin{array}{l}\text { Year graduated Management } \\
\text { School }\end{array}$ & 1993 (1965-2014) \\
\hline \multicolumn{2}{|l|}{ Institution where attained MBA } \\
\hline $\begin{array}{c}\text { University at Buffalo, State } \\
\text { University of New York }\end{array}$ & 47 (69) \\
\hline Other & $21(31)$ \\
\hline \multicolumn{2}{|l|}{$\begin{array}{l}\text { Earn MBA concurrently in } \\
\text { pharmacy school? }\end{array}$} \\
\hline Yes, while in pharmacy school & $40(59)$ \\
\hline No, at other time & $28(41)$ \\
\hline \multicolumn{2}{|l|}{ Completed post-graduate training? } \\
\hline No & $52(76)$ \\
\hline Yes, residency & $10(15)$ \\
\hline Yes, fellowship & $4(6)$ \\
\hline Yes, other & $2(3)$ \\
\hline \multicolumn{2}{|l|}{$\begin{array}{l}\text { Current position is my entry-level } \\
\text { position? }\end{array}$} \\
\hline Yes & $21(31)$ \\
\hline No & 47 (69) \\
\hline \multicolumn{2}{|l|}{ Am I retired? } \\
\hline Yes & $4(6)$ \\
\hline No & $64(94)$ \\
\hline
\end{tabular}

Data are presented as N (\%) for categorical data and median (range) for continuous data alumni who obtained both pharmacy and MBA degrees. We will refer to a pharmacy degree as an individual who obtained a BS Pharmacy or PharmD degree. The survey population was attained from alumni lists encompassing all graduates from the two programs. Both lists were cross-referenced and duplicates were excluded. Additionally, subjects were included if they attained their pharmacy degree from UB and an MBA from an outside institution with a separate alumni list generated to ascertain these individuals. Subjects were excluded if their contact information was unavailable, they did not want to be contacted by UB for research purposes or if their terminal management degree was not an MBA. Based on these criteria, a total of 115 pharmacy/MBA graduates were eligible for study participation. The survey instrument was administered via e-mail with a link to the survey using a secure online application, Qualtrics (Qualtrics, LLC, Provo, UT) over a six-week period in winter 2015. A reminder e-mail was sent three weeks after initial mailing to encourage study participation. All participation was voluntary and respondents were not offered any compensation. This study was approved by the Social and Behavioral Institutional Review Board at the University at Buffalo.

The survey instrument was developed by a multidisciplinary team including two pharmacists with an MBA, an assistant dean from the UB School of Management, and a researcher with experience in survey methodology. Published literature was reviewed for validated survey instruments related to the current study, but no useful tools were found. The questionnaire was pilot tested among pharmacists with MBAs for readability, length and relevance of specific items. Pilot testing resulted in only minor changes and established an estimated completion time for prospective study participants.

The survey instrument consisted of three sections totaling 30 questions. Data collected from section 1 included: age, gender, year of graduation from pharmacy and management school, institution where management degree was obtained, any post-graduate training, and whether the participant was in their entry-level position. Sections 2 and 3 collected data on an individual's entrylevel and current positions. Questions from this section were similar and included: position title, company and state of employment, position setting, annual salary, quantitative assessment of utilization of pharmacy and MBA degrees, and assessment of subjects' attitudes toward their combined degree. Entry-level position was defined as the subject's first position following completion of both their pharmacy and MBA degrees. Post-graduate training including residency and fellowship were included as an entry-level position. Current positions were defined 


\section{American Journal of Pharmaceutical Education 2017; 81 (4) Article 72.}

Table 2. Characteristics of Pharmacy/MBA Professionals During Their Entry-level and Current Positions

\begin{tabular}{lcc}
\hline Characteristic & Entry-Level Position (N=68) & Current Position (N=47) \\
\hline Currently in Entry Level Position & $21(31)$ & - \\
Location of Position & & \\
$\quad$ New York & $41(60)$ & $23(51)^{\mathrm{a}}$ \\
Other & $27(40)$ & $22(49)^{\mathrm{a}}$ \\
Year Started Position & $1991(1985-2006)$ & $2007(1999-2012)$ \\
Time Between Entry-level and Current Positions, Years & & \\
Mean (SD) & $15(9.4)$ & \\
Median (IQR) & $15(6.5-24)$ & $176,947(141,777-230,704)$ \\
Mid-range Salary, Median (IQR), US\$ $\$^{\mathrm{d}, \mathrm{e}}$ & $143,186(103,830-176,420)$ & $205,623(91,329)$ \\
Mid-range Salary, Mean (SD), US\$ ${ }^{\mathrm{d}, \mathrm{f}}$ & $144,327(53,382)$ & $\mathrm{N}=44$ \\
Mid-range Salary, Categorical, US\$ $\$$ & $\mathrm{~N}=64$ & 0 \\
$\leq 50,000$ & 0 & 0 \\
$>50,000-100,000$ & $15(23)$ & $11(25)$ \\
$>100,000-150,000$ & $19(30)$ & $15(34)$ \\
$>150,000-200,000$ & $22(35)$ & $10(23)$ \\
$>200,000-250,000$ & $6(9)$ & $8(18)$ \\
$>250,000$ & $2(3)$ & \\
\hline
\end{tabular}

Data are presented as N (\%) for categorical variables and median (IQR) for continuous variables, unless otherwise noted

${ }^{\mathrm{a}}$ Two missing observations

${ }^{\mathrm{b}}$ Three missing observations

${ }^{\mathrm{c}}$ Four missing observations

${ }^{d} 43$ subjects had data between entry-level and current positions and were not in their post-graduate training at time of entry-level position

${ }^{\text {e}}$ Statistically significant difference $(p<.001)$ using a Wilcoxon signed-rank test

${ }^{\text {f }}$ Statistically significant difference $(p<.01)$ using a paired $t$-test

${ }^{\mathrm{g}}$ Statistically significant difference $(p<.0001)$ using a Fisher's exact test

as the subject's present employment at time of survey application and was only asked if the subject indicated he/she was in a non-entry level position. In order to enhance response, salary was originally collected as a categorical variable in $\$ 10,000$ increments up to $\$ 100,000$, thereafter $\$ 25,000$ increments up to $\$ 1,000,000$. The utilization and helpfulness of pharmacy and MBA degrees in both entrylevel and current positions were scored through a constant sum mechanism ranging from 0 to $100 \%$ (respondent's sum could not exceed $100 \%$ between both degrees). Subjects' attitudes were scored on a 5-point Likert scale ranging from $1=$ strongly disagree to $5=$ strongly agree . Additional questions were multi-answer formats including multiple choice, categorical, or fill in the blank.

Descriptive statistics were calculated to summarize respondents' characteristics. All salary data was adjusted for inflation to 2014 dollars using the consumer price index through the Bureau of Labor Statistics. ${ }^{6}$ A continuous variable for salary was created as a mid-range salary variable taking the average between the base and upper level categories following adjustment for inflation. For the continuous salary variable, we assessed differences in salary between entry-level and current position by taking only those respondents who answered the questions for both time periods and were not a post-graduate trainee in their entry-level position. For the categorical salary variable, we assessed all salary responses within the survey in order to provide a thorough presentation of the salary variable. We presented salary as its mean \pm standard deviation, median (interquartile range) to account for a non-normal distribution, and as a categorical variable in $\$ 50,000$ increments. Differences in salary were assessed by the Wilcoxon signed-rank test or paired $t$-test for the continuous variable and Fisher's exact test for the categorical variable. Additional categorical analyses utilized the chi-square or Fisher's exact test, as appropriate. Not all respondents answered each question, and thus numbers were adjusted for each item. All statistical analyses were performed using SAS, version 9.4. (SAS Institute, Cary, NC).

\section{RESULTS}

A total of 68 out of 115 pharmacy/MBA graduates completed the survey, signifying a 59\% response rate. The majority of respondents were male (72\%) and the median age was 49 years (Table 1). The respondents' median (range) graduation year from pharmacy school was 1988 (1951-2014) and from management school was 1993 (1965-2014). Most respondents (69\%) attained their MBA from UB and 59\% completed their MBA concurrently with pharmacy school. Post-graduate training 
was completed by $24 \%$ of respondents and most commonly it was a residency program.

Of the 68 respondents, 21 (31\%) were currently in their entry-level position, and $47(69 \%)$ respondents were in their current position (Table 2). The location of entrylevel position were most commonly New York state $(60 \%)$, however this decreased to $51 \%$ as respondents moved into their subsequent current position. We had 43 respondents with completed salary data for both their entry-level and current positions. After adjustment for inflation in 2014 US dollars, the median mid-range salary for entry-level graduates was $\$ 140,123$ and this increased to a median salary of $\$ 179,947$ within their current position $(P<.001)$. If we look at all respondents at entry-level $(n=64)$ and at their current position $(n=44)$, we see the number of individuals with salaries above $\$ 200,000$ increased from $12 \%$ to $41 \%(P<.0001)$.

Within their entry-level positions, respondents indicated they utilized $71 \%$ of their pharmacy degree and $29 \%$ of their management degree (Figure 1A). As they progressed to their current positions, the utilization of the management degree increased to $50 \%(P<.0001)$. Similar findings were seen when respondents indicated the helpfulness of both degrees to obtain employment (Figure 1B). The helpfulness of a pharmacy degree to obtain employment at entry-level was $73 \%$, but decreased to $52 \%$ within their current position $(P<.0001)$. A subsequent increase in the helpfulness of the management degree to obtain their present position was seen. The most common practice settings for entry-level professionals were pharmaceutical industry, chain pharmacies $(4+$ units) and hospital pharmacies (Table 3). Practice settings for post-entry level pharmacy/MBA professionals were similar to entry-level with a slight increase in employment in academic settings.

Respondents agreed that earning both pharmacy and MBA degrees made them more competitive in the job market (Table 4). Respondents were overwhelmingly satisfied with both degrees regardless of position. Also, most respondents would recommend earning an MBA in addition to a pharmacy degree. There were no significant differences in perceptions based on entry-level or current position perspectives.

\section{DISCUSSION}

To our knowledge, this is the first article to examine perceptions, attitudes and outcomes related to pharmacy/ MBA professionals. Dual degree programs provide an opportunity for pharmacists to develop specialized insights in a separate field, along with additional experiences. ${ }^{7}$ An MBA has become the most prevalent professional degree associated with the PharmD in the
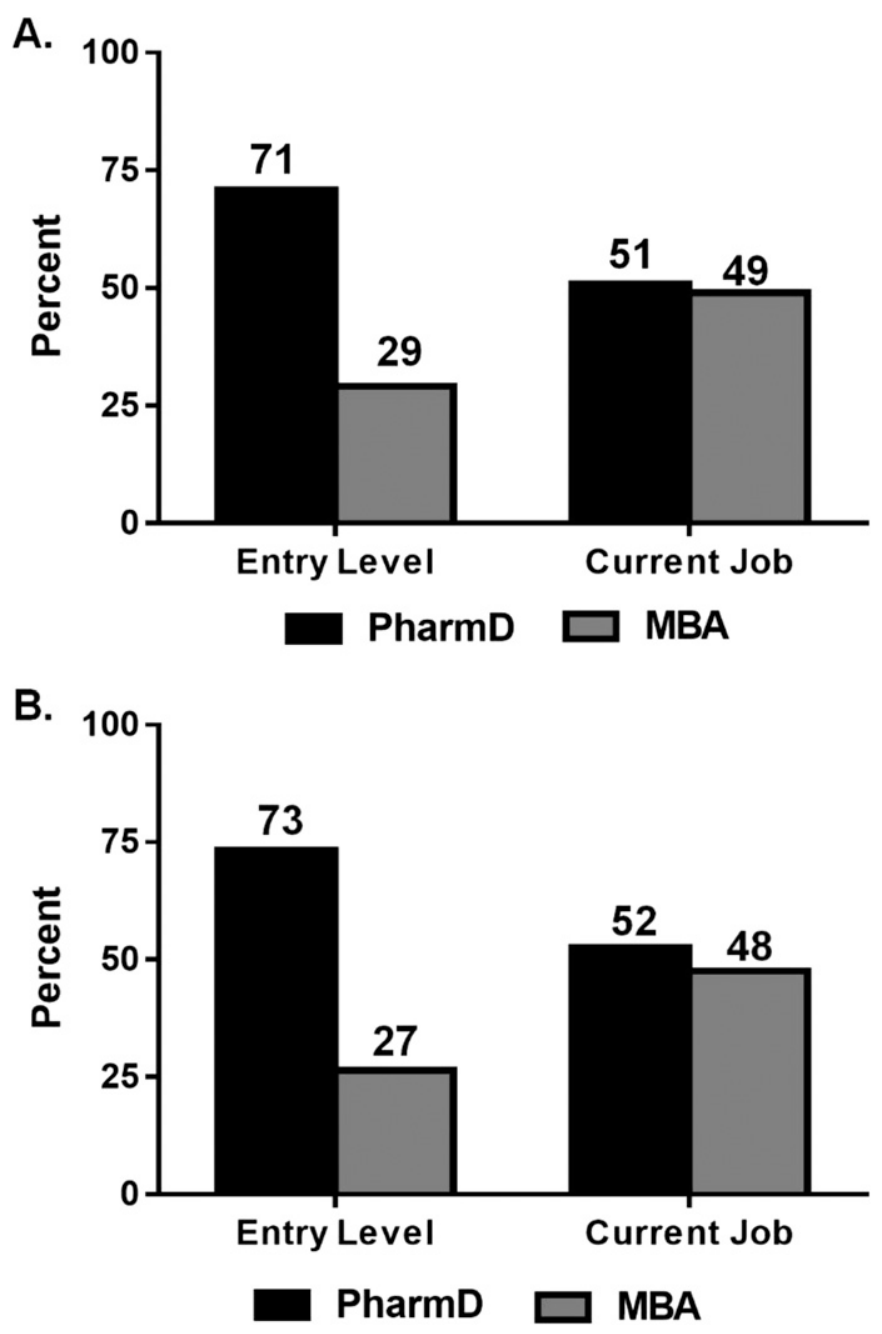

Figure 1. Change over time of utilization of pharmacy and MBA degrees within participants' jobs (A) and helpfulness of pharmacy and MBA degrees to obtain employment (B). A significant increase $(P<.0001)$ in utilization and helpfulness of MBA degree was seen between entry level and current job.

United States and recently the UB SPPS has seen a surge in the number of students participating in this dual degree program. ${ }^{1,8}$ This may be due to the recent increase in pharmacy graduates, or that students may see the potential an MBA can have on their careers. However, the literature is sparse when it comes to graduates of combined programs in terms of career trajectories and present positions of graduates of these programs.

We found the mid-range median and mean salaries for entry-level pharmacy/MBA professionals after adjustment for inflation to be $\$ 143,186$ and $\$ 144,327$, respectively. These findings were similar to Chumney and colleagues where they looked at PharmD/MBA graduates in 2007. They found an average 2014 adjusted starting salary for those moving into an entry-level position to be $\$ 125,696$. This study had a relatively small sample size of 13 PharmD/ 


\section{American Journal of Pharmaceutical Education 2017; 81 (4) Article 72.}

Table 3. Pharmacy/MBA Professionals’ Employment Settings

\begin{tabular}{lcc}
\hline Settings & $\begin{array}{c}\text { Entry-Level } \\
\text { (N=65) No. }(\%)\end{array}$ & $\begin{array}{c}\text { Current (N=47) } \\
\text { No. }(\%)\end{array}$ \\
\hline $\begin{array}{l}\text { Pharmaceutical Industry } \\
\text { Chain Pharmacy (4+ } \\
\quad \text { units) }\end{array}$ & $16(25)$ & $9(19)$ \\
$\begin{array}{l}\text { Hospital/Institutional } \\
\quad \text { inpatient pharmacy) }\end{array}$ & $10(15)$ & $6(13)$ \\
$\begin{array}{l}\text { Managed Care Pharmacy } \\
\text { Other }\end{array}$ & $7(11)$ & $2(9)$ \\
Independent Pharmacy & $7(11)$ & $9(19)$ \\
$\quad(1-3$ units) & $5(8)$ & $2(4)$ \\
Management Focused & $3(5)$ & $3(6)$ \\
Residency or Fellowship & $3(5)$ & $5(11)$ \\
Clinic (outpatient) & $1(2)$ & $2(4)$ \\
$\quad$ Pharmacy & $1(2)$ & 0 \\
Federal Pharmacy & 0 & $4(9)$ \\
College or School of & & $1(2)$ \\
$\quad$ Pharmacy (academia) & & \\
Consultant Pharmacy & 0 &
\end{tabular}

MBA graduates in a short time period, but were able to show a significantly higher mean salary for dual degree students compared to PharmD graduates. To our knowledge, no further data exist that specifically assesses PharmD/MBA professionals, and a comparison to national salary data of mixed degree and experienced pharmacists would be inappropriate. Interestingly, as dual degree pharmacists continued in their career, we saw their salary increase to where over $40 \%$ of our sample were making at least $\$ 200,000$. An increase in reliance on their MBA degree was seen as these individuals advanced professionally, which may have an impact on their overall salary. Furthermore, salary usually increases with time, years of experience, and performance, therefore based on the abovementioned factors we believe this to be a valid estimation. Also, over the past 20 years there was an increase in pharmacist salaries due to the pharmacist shortage in the late 1990s and early 2000s. Those pharmacists in the workforce with an MBA at that time may have benefited from this shortage.

This study demonstrated that pharmacy/MBA professionals had a positive view on the influence an MBA had on their careers. Almost all respondents believed that earning an MBA made them more competitive in the job market throughout their careers. As the number of pharmacy graduates continue to increase, students are interested in ways to distinguish themselves. In a recent survey of PharmD/MBA students at UB SPPS, we found that job market competitiveness and marketability were the two most important aspects of pursuing an MBA degree. ${ }^{8}$ Overall, approximately $80 \%$ of our pharmacy/MBA professionals would recommend an MBA in addition to a pharmacy degree. We believe an MBA or any secondary degree along with a PharmD would be beneficial for a student or current practitioner. An additional degree can provide a unique set of tools and points of view in the ever changing health care environment.

We found that post-graduate training among this cohort was rather uncommon. Only $24 \%$ of respondents indicated any type of training after graduation. Similar findings were seen in the article by Chumney and colleagues, where $17 \%$ of PharmD/MBA students were entering a residency. ${ }^{5}$ Our survey at UB SPPS showed $48 \%$ of PharmD/MBA students plan on pursuing some type of post-graduate training. ${ }^{8}$ These dissimilar findings between past and present graduates are not surprising. Previously, there was a shortage of pharmacists and a limited number of individuals trained for managerial roles. We expect a pharmacy and MBA degree was sufficient to attain their targeted entry-level position. With the shortage of pharmacists over and an upsurge of pharmacy students graduating annually, students are looking to distinguish themselves through secondary degrees

Table 4. Pharmacy/MBA Professionals' Attitudes and Perceptions About the Benefits of Their Combined Degree

\begin{tabular}{|c|c|c|}
\hline \multirow[b]{2}{*}{ Perceptions and Attitudes } & \multicolumn{2}{|c|}{ Strongly Agree / Agree a,b $^{a}$} \\
\hline & $\begin{array}{c}\text { Entry-Level } \\
(\mathrm{N}=68) \%\end{array}$ & $\begin{array}{c}\text { Current Position } \\
(\mathrm{N}=46) \%\end{array}$ \\
\hline Earning Pharmacy/MBA degrees helped me in my career advancement & 79 & $85^{\mathrm{b}}$ \\
\hline Earning Pharmacy/MBA degrees made me more competitive in the job market & 92 & 90 \\
\hline I am satisfied with my Pharmacy/MBA degrees & $94^{\mathrm{b}}$ & 87 \\
\hline Devoting extra time in the coursework for the MBA degree was worth the effort & 88 & 83 \\
\hline Earning Pharmacy/MBA degrees provided a positive return on my investment & 79 & 85 \\
\hline Earning Pharmacy/MBA degrees increased my opportunities to network & $79^{\mathrm{c}}$ & $75^{\mathrm{c}}$ \\
\hline I would recommend earning an MBA in addition to a Pharmacy degree & $82^{\mathrm{c}}$ & $78^{\mathrm{c}}$ \\
\hline
\end{tabular}

assessed via Chi-square or Fisher's exact test

${ }^{\mathrm{b}}$ No significant differences were found between groups

${ }^{\mathrm{c}}$ One missing observation 


\section{American Journal of Pharmaceutical Education 2017; 81 (4) Article 72.}

and additional training. Interestingly, the changes in the existing pharmacy environment may help produce the leaders we need for tomorrow's challenges through additional coursework and training.

There are limitations to our study. First, our study is limited by recall bias as we were asking questions about two different time periods within the respondents' employment history. We believe that salary data would be the most skewed response participants would provide. As our salary findings at entry-level were relatively close to a previous study, we believe that recall bias may be limited. ${ }^{5}$ Also, as our salary calculation was based on a mid-range salary, which was ascertained from a categorical variable, we expect some error in our calculation. As our median mid-range salary was within $15 \%$ of previous literature, we believe this error was minimal. ${ }^{5} \mathrm{Un}$ fortunately, for our salary findings among individuals in their current positions we were not able to find a comparator within the literature. Also, within our salary analysis we adjusted for inflation, but were not able to account for changes in salary based on different influences over time. Second, most respondents to our survey were individuals who practiced in New York where salaries and the cost of living are higher than national rates. This may have accounted for the higher salary ranges that we saw for this sample. Furthermore, we did not assess cost of living in the areas where our subjects practiced, which can also impact salary. Finally, our response rate was not ideal, however we did achieve the approximate $60 \%$ response rate suggested by the Journal for survey research. ${ }^{9}$ As our cohort is inclusive of pharmacists that attained an MBA degree from outside the University at Buffalo, we believe this increases the external validity of our study. Also, individuals with a pharmacy and MBA degree make up a small number of the total pharmacists in the workforce. ${ }^{10}$ The number of respondents to the survey $(\mathrm{N}=68)$ is relatively large considering the population and enough to make valid conclusions.

Further research in pharmacy-based dual degrees beyond the MBA should be undertaken especially as we are seeing an increase in dual degree students and programs. Career trajectories of these individuals should be ascertained in order to justify the time and resources necessary to embark on a secondary or tertiary degree. Of particular interest would be an interprofessional approach that includes nursing, medical, dental and public health programs.

\section{CONCLUSIONS}

This study is the first published formal assessment of pharmacy/MBA professionals and analyses of their experiences. Combined pharmacy/MBA professionals are well-compensated and are in a wide range of professional settings. They have a high-level of satisfaction with their degrees and would recommend earning an MBA in addition to a pharmacy degree. It is unknown whether these findings translate to other dual degree pharmacy professionals including those with a $\mathrm{PhD}, \mathrm{JD}, \mathrm{MPH}$ or MS. Further research is needed in these areas especially as dual degree programs in schools of pharmacy continue to increase across the country.

\section{REFERENCES}

1. American Association of Colleges of Pharmacy. Dual-degree programs anticipated for 2015-16. http://www.aacp.org/resources/ student/pharmacyforyou/admissions/admissionrequirements/ Documents/PSAR\%201516\%20-\%20Table\%204.pdf. Accessed November 10, 2015.

2. University at Buffalo School of Management. PharmD/MBA. http://mgt.buffalo.edu/degree-programs/master-of-business-mba/ academic-options/dual-collaborative/pharmd-pharmacy.html. Accessed November 10, 2015

3. American Association of Colleges of Pharmacy. Academic pharmacy's vital statistics. http://www.aacp.org/about/Pages/ Vitalstats.aspx. Accessed November 10, 2015.

4. Nelson S, Andritz M, Davis P. Dual Degree Task Force white paper. http://www.aacp.org/governance/councildeans/Documents/ White $\% 20$ Paper $\% 20$ on $\% 20$ the $\% 20$ Role $\% 20$ of $\% 20$ Schools $\% 20$ in $\%$ 20Dual\%20Degree\%20programs.pdf. Accessed on November 10, 2015.

5. Chumney ECG, Ragucci KR, Jones KJ. Impact of a dual PharmD/ MBA degree on graduates' academic performance, career opportunities, and earning potential. Am J Pharm Educ. 2008;72(2): Article 26.

6. Bureau of Labor Statistics. Consumer Price Index. http://www.bls. gov/cpi/. Accessed July 25, 2015.

7. Shannon SB, Bradley-Baker LR, Truong H-A. Pharmacy residencies and dual degrees as complementary or competitive advanced training opportunities. Am J Pharm Educ. 2012;76(8): Article 145.

8. Jacobs DM, Tierney S-EL, O'Brien E, Fiebelkorn KD, Daly CJ. Current attitudes and perceptions of dual PharmD/MBA degree program students. Am J Pharm Educ. 2015;79(5):Article S4. 9. Fincham JE. Response rates and responsiveness for surveys, standards, and the Journal. Am J Pharm Educ. 2008;72(2):Article 43. 10. American Association of Colleges of Pharmacy. 2014 National Pharmacist Workforce Survey. http://www.aacp.org/resources/ research/pharmacyworkforcecenter/Documents/ FinalReportOfTheNationalPharmacistWorkforceStudy2014.pdf. Accessed February 22, 2016. 